\title{
Segmentasi Tulang Kortikal pada Citra Dental Panoramic Radiograph
}

\author{
Thohiroh Agus Kumala*1, Agus Harjoko ${ }^{2}$ \\ ${ }^{1}$ Prodi S2/S3 Ilmu Komputer, FMIPA UGM, Yogyakarta \\ ${ }^{2}$ Jurusan Ilmu Komputer dan Elektronika, FMIPA UGM, Yogakarta \\ e-mail : *11 thohiroh_agus@yahoo.com.sg, ${ }^{2}$ aharjoko@ugm.ac.id
}

\begin{abstract}
Abstrak
Pengolahan citra dalam dunia medis sudah banyak dikembangkan. Satu tahapan yang penting dalam pengolahan citra ini yaitu segmentasi. Ketepatan dalam menentukan diagnosis suatu penyakit ditentukan oleh ketepatan tahap segmentasi.

Penelitian ini menggunakan citra dental panoramic radiograph dengan ukuran $2000 \times 1000$ piksel. Daerah sampel tulang kortikal diambil dari tulang kortikal rahang bawah bagian kanan dan kiri sekitar foramen mentalis dengan ukuran $128 x 128$ piksel. Untuk mempermudah proses segmentasi maka dilakukan prapengolahan terhadap citra yaitu dengan contrast stretching dan grayscaling. Selanjutnya citra hasil prapengolahan dilakukan segmentasi menggunakan metode active contour. Metode ini diawali dengan pembentukan pembentukan mask sebagai kurva awal, dari kurva awal ini kemudian kurva akan bergerak keluar atau kedalam sesuai dengan bentuk tepi dari tulang kortikal.

Ujicoba dilakukan dengan menggunakan metode ROC (Receiver Operating Characteristic). Segmentasi dari 21 data citra dental panoramic radiograph menggunakan metode Active Contour dapat melakukan segmentasi tulang kortikal kanan dengan prosentase akurasi 90,67\%, sensitifitas 90,14\% dan spesifitas 91,55\%. Tulang kortikal kiri dengan prosentase akurasi $89,37 \%$, sensitifitas $86,59 \%$ dan spesifitas $91,23 \%$.
\end{abstract}

Kata kunci-active contour, dental panoramic radiograph, tulang kortikal, segmentasi citra

\begin{abstract}
Image processing in the medical world has been developed. One important stage in the processing of this image is segmentation. The accuracy in determining the diagnosis of a disease is determined by the accuracy of the segmentation stage.

This study used a dental panoramic radiograph image with the size of 2000x1000 pixels. The area of cortical bone samples taken from the cortical bone of the lower jaw right and left about the mental foramen with $128 \times 128$ pixels. To simplify the process of segmentation is carried out preprocessing on the image that is by contrast stretching and grayscale. Furthermore, image segmentation results of preprocessing conducted using active contour method. This method begins with the formation of the formation of the mask as the initial curve, from the initial curve is then the curve will move in or out according to the shape of the edge of the cortical bone.

Tests performed using the ROC (Receiver Operating Characteristic). Segmentation of 21 dental panoramic radiograph image data using Active Contour method can perform with the right cortical bone segmentation accuracy percentage of $90.67 \%, 90.14 \%$ sensitivity and $91.55 \%$ specificity. Cortical bone is left with an accuracy percentage of $89.37 \%, 86.59 \%$ sensitivity and $91.23 \%$ specificity.
\end{abstract}

Keywords - active contour, dental panoramic radiograph, cortical bone, image segmentation

Received February $27^{\text {th }}, 2015$; Revised April 13 ${ }^{\text {th }}, 2016$; Accepted April 29 ${ }^{\text {th }}, 2016$ 


\section{PENDAHULUAN}

Dental panoramic radiograph ini biasanya digunakan dalam ilmu kedokteran gigi untuk menganalisis kesehatan gigi dan mulut pasien. Dengan perkembangan penelitian menggunakan citra dental panoramic radiograph ini maka pemanfaatannya dapat diperluas untuk mendeteksi adanya tumor pada mulut maupun osteoporosis. Osteoporosis merupakan penyakit yang diakibatkan oleh adanya penurunan massa (densitas) tulang yang disertai dengan peningkatan porositas tulang.

Penggunaan citra dental panoramic radiograph dalam mendeteksi osteoporosis ini dilakukan dengan mengukur ketebalan kortikal tulang rahang bawah atau mandibula. Implementasi pengukuran lebar kortikal pada bagian kanan dan kiri tulang mandibula ini telah dipatenkan di negara Jepang oleh peneliti [1]. Foramen mentalis dalam citra dental panoramic radiograph terlihat seperti lingkaran hitam yang terletak antara gigi premolar dan gigi molar 1. Gambar 1 menunjukkan suatu citra medis dental panoramic radiograph dan Gambar 2 menunjukkan area of interest yaitu tulang kortikal kanan dan kortikal kiri sekitar foramen mentalis.

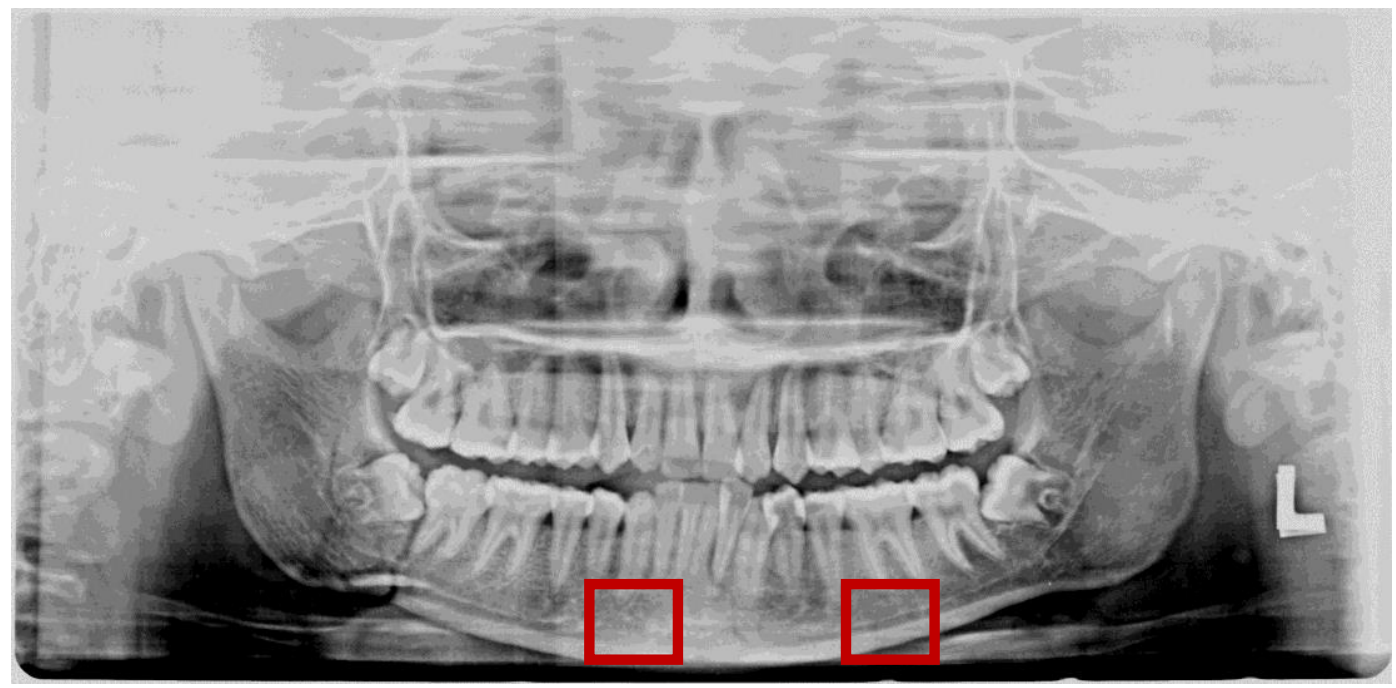

Gambar 1 Citra medis dental panoramic radiograph
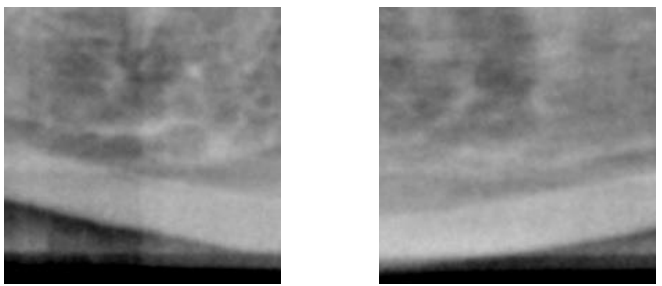

Gambar 2 Tulang kortikal kanan dan kortikal kiri sekitar foramen mentalis

Dalam perhitungan ketebalan kortikal maka diperlukan ketepatan dan ketelitian untuk menentukan mana bagian yang tergolong bagian kortikal dan mana yang merupakan latar belakang, karena seorang dokter atau radiolog biasanya menentukan batas tulang kortikal dilakukan secara subyektif, sehingga antara dokter yang satu dengan lainnya memiliki perbedaan dalam menganalisis hasil. Untuk membantu hal ini maka diperlukan adanya segmentasi yang dapat membantu menentukan bagian-bagian tersebut.

Untuk mengatasi permasalahan tersebut diatas maka diperlukan suatu teknologi yang dapat dengan jelas menampilkan informasi yang dibutuhkan, sehingga pada penelitian ini akan dibuat suatu program yang dapat melakukan segementasi tulang kortikal secara otomatis dengan

IJEIS Vol. 6, No. 1, April 2016 : $37-46$ 
menggunakan media masukkan berupa citra dental panoramic radiograph. Program ini dibuat dengan menggunakan metode active contour karena metode tersebut dapat melakukan segmentasi pada topologi yang berbeda, obyek dengan tepi yang kurang tajam dan segmentasi pada garis serta kurva yang tidak tertutup. Metode Geometric active contour yang digunakan adalah Chan Vese.

Penelitian sebelumnya [2] mempelajari citra medis Dental Panoramic Radiograph. Daerah citra yang diambil adalah bagian tulang mandible tanpa menyertakan bagian akar gigi dan cortical tulang mandible dan tidak harus pada bagian foramen mentalis. Bagian ini kemudian dilakukan perbaikan citra dan binerisasi. Hasil dari proses penentuan obyek berupa citra biner, nilai nol dan satu dari citra biner dijadikan acuan pembentukan graph. Pemberian bobot graph dilakukan dengan cara, jika jarak natara piksel bernilai satu dekat, bobot cenderung mendekati 1. Untuk menentukan nilai karakter graph, karakter yang dihitung adalah degree dan cluster coefficient. Cluster coefficient digunakan untuk keterhubungan antara piksel bernilai 1 dan degree digunakan untuk menentukan kerapatan dari sebuah graph.

Penelitian ini akan membuat suatu sistem yang digunakan untuk melakukan segmentasi tulang kortikal pada suatu citra dental panoramic radiograph. Tulang kortikal yang diambil sebagai sampel adalah tulang kortikal yang letaknya berada tepat di bawah foramen mentalis mandibula. Penelitian ini dalam segmentasinya menggunakan metode active contour Chan Vese. Chan Vese secara teori dapat menjamin kecepatan, kehandalan dan akurasi citra medis yang memiliki tepi kurang jelas (kabur)[3].

\section{METODE PENELITIAN}

Diagram alir metode penelitian untuk segmentasi tulang kortikal pada citra dental panoramic radiograph ditunjukkan oleh Gambar 3.



Gambar 3 Diagram alir penelitian 


\subsection{Akuisisi Citra}

Citra yang digunakan adalah medis dental panoramic radiograph dalam bentuk file citra dengan format Joint Experts Group (*.jpeg). Citra masukkan ini berukuran 3000 x 2000 piksel, sehingga untuk mempermudah dalam menentukan foramen mentalis dan mempercepat proses maka dibuat menjadi 2000x1000 piksel.

\subsection{Prapengolahan}

Prapengolahan dalam penelitian ini ada beberapa tahapan yaitu pengambilan sampel tulang kortikal, grayscaling dan contrast stretching.

\subsubsection{Pengambilan sampel tulang kortikal}

Pengambilan tulang kortikal dilakukan secara manual dengan melakukan cropping pada dua daerah sampel sebesar $128 \times 128$ piksel yaitu $(622,872,128,128)$ untuk kortikal kanan dan $(1250,872,128,128)$ untuk kortikal kiri. Daerah ini diambil karean rata-rata dari 21 data citra yang diperoleh memiliki daerah sekitar foramen mentalis pada piksel tersebut.

\subsubsection{Grayscaling}

Grayscaling disini sebenarnya digunakan untuk memastikan bahwa masukkan yang digunakan dalam bentuk Grayscale. Proses grayscaling dilakukan dengan menghitung nilai semua piksel kemudian dilakukan persamaan kedalam skala keabuan. Dalam penelitian ini untuk proses grayscaling setiap piksel yang akan dirubah menjadi abu mengunakan koefisien 0.299 untuk merah, 0.587 untuk hijau dan untuk biru 0.114. Persamaan (1) yang digunakan,

$$
f_{0}(x, y)=\frac{f_{i}^{R}(x, y)+f_{i}^{G}(x, y)+f_{i}^{B}(x, y)}{3}
$$

\subsubsection{Contrast stretching}

Untuk mendapatkan citra baru $\mathrm{f}_{0}(\mathrm{x}, \mathrm{y})$ dengan kontras yang lebih baik daripada kontras citra asalnya $\mathrm{f}_{\mathrm{i}}(\mathrm{x}, \mathrm{y})$ maka menggunakan contrast stretching dengan ide dari proses contrast stretching yaitu untuk meningkatkan range dinamis dari level grayscale pada citra saat pemrosesan berlangsung.

Jika $r_{1}=r_{2}$ dan $s_{1}=s_{2}$ maka transformasi akan berbentuk garis lurus, artinya tidak ada perubahan gray level pada citra yang dihasilkan. Secara umum diasumsikan $r_{1} \leq r_{2}$ dan $s_{1} \leq s_{2}$ sehingga fungsi akan menghasilkan nilai tunggal dan nilainya akan selalu naik.

Untuk menghitung nilai hasil transformasi, maka dibuat tiga fungsi yang ditunjukkan pada persamaan (2) - (4) sebagai berikut :

$$
\begin{aligned}
& \text { Untuk } 0 \leq f_{i}(x, y)<r_{1} \text {, maka } \\
& \qquad f_{0}(x, y)=f_{i}\left(x, \cdots \frac{s_{1}}{r_{1}}\right. \\
& \text { Untuk } r_{1} \leq f_{i}(x, y)<r_{2} \text {, maka } \\
& \qquad f_{0}(x, y)=s_{1}+\left(f_{i}(x, y)-r_{1}\right) \frac{s_{2}-s_{1}}{r_{2}-r_{1}}
\end{aligned}
$$

Untuk $r_{2} \leq f_{i}(x, y) \leq 255$, maka

$$
f_{0}(x, y)=s_{2}+\left(f_{i}(x, y)-r_{2}\right) \frac{255-s_{2}}{255-r_{2}}
$$




\subsection{Active contour}

Pada metode Geometric Active Contour ini prosesnya mengikuti diagram alir yang ditunjukkan pada Gambar 4.

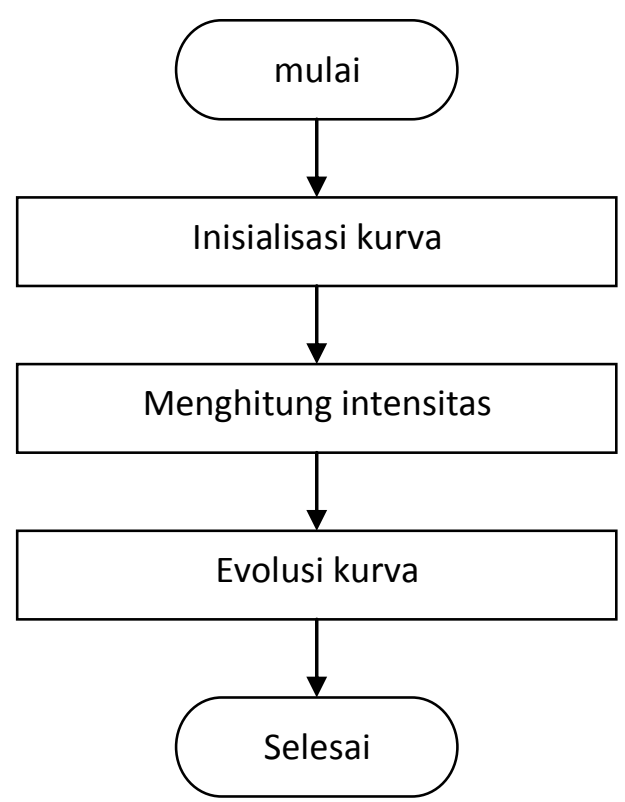

Gambar 4 Diagram alir active contour

\subsubsection{Inisialisasi kurva}

Inisialisasi kurva diawali dengan menentukan parameter control, bobot atau konstanta energi internal dan eksternal. Kemudian langkah berikutnya yaitu membentuk mask dan SDF, inisialisasi ini berbentuk kotak dimana kurva inilah yang dinamakan zero level set $\Phi(x, t=0)$. Pada proses inisialisasi ini, terdapat informasi yang digunakan untuk menghitung jarak. Proses perhitungan jarak dari suatu titik terhadap kurva inisialisasi ini bermanfaat untuk mendeteksi dimana kurva berada. Proses untuk menghitung jarak menggunakan perhitungan Euclidean distance. Setelah mendapatkan nilai dari jarak maka diperiksa apakah titik tersebut berada dalam kurva atau tidak, jika nilai jarak lebih besar dari nol maka titik berada diluar kurva. Sebaliknya, jika nilai jarak lebih kecil dari nol maka titik berada di dalam kurva.

\subsubsection{Menghitung intensitas}

Langkah kedua menghitung intensitas rata-rata menggunakan persamaan (5), dan untuk mempercepat proses perhitungan dari metode Level Set. Active contour merupakan sebuah proses minimisasi energi, dimana batasan dari obyek merupakan nilai minimum dari fungsi energi. Fungsi energi tersebut bukan hanya terdiri dari informasi mengenai tepi objek, melainkan juga berisi properti yang mengontrol pergerakan dari kurva itu sendiri.

$$
\begin{aligned}
f\left(c_{1}, c_{2}, \emptyset\right)= & \mu \int_{\Omega} \delta(\varnothing(x, y))|\nabla \emptyset(x, y)| d x d y+v \int_{\Omega} H(\varnothing(x, y)) d x d y \\
& +\lambda_{1} \int_{\Omega}\left|\mu_{0}(x, y)-c_{1}\right|^{2} H(\varnothing(x, y)) d x d y \\
& +\lambda_{2} \int_{\Omega}\left|\mu_{0}(x, y)-c_{2}\right|^{2}(1-H(\varnothing(x, y))) d x d y
\end{aligned}
$$


Pada tahap ini juga menentukan tepi citra sebagai energi eksternal dengan menentukan gradient dari citra, dimana fungsi edge ditunjukkan pada persamaan (6).

$$
g=\frac{1}{1+|\nabla G \sigma \times I|^{2}}
$$

Energi eksternal ditunjukkan pada persamaan (7).

$$
\varepsilon_{g, \lambda, v}(\varnothing)=\lambda \cdot L_{g}(\varnothing)+V \cdot A_{g}(\varnothing)
$$

Menghitung energi internal sebagai fungsi jarak ditunjukkan pada persamaan (8).

$$
\varepsilon(\varnothing)=\mu \cdot P(\varnothing)+\varepsilon_{m}(\varnothing)
$$

\subsubsection{Evolusi kurva}

Langkah ketiga yaitu evolusi kurva, proses evolusi menggunakan metode level set untuk menggerakkan kurva sehingga kurva dapat mengembang atau mengempis sampai memenuhi kondisi untuk berhenti.

\subsection{Validasi}

Karakteristik dari digitisasi citra objek yang diteliti berhubungan erat dengan kualitas citra yang dihasilkan. Hal tersebut telah terbukti dapat mempengaruhi bentuk kurva hubungan antara TPR dan FPR pada setiap analisis medis berbasis citra digital[4].

Validasi dalam penelitian ini menggunakan receiver operating characteristic (ROC) untuk mengukur kinerjanya. Kami membandingkan hasil prediksi dari hasil segmentasi menggunakan metode active contour dan hasil manual dengan menghitung piksel yang bernilai true positive, true negative, false positive dan false negative. Kemudian menghitung true positive rate, false positive rate dan akurasi.

Grafik Receiver Operating Characteristic (ROC) adalah teknik untuk memvisualisasikan, mengatur dan memilih pengklasifikasi berdasarkan kinerja [5]. Selain itu dapat dihitung pula AUC (Area Under Curve). Tabel kategori pengklasifikasi menurut nilai AUC dapat dilihat pada Tabel 1.

Tabel 1 Tabel kategori pengklasifikasi berdasarkan nilai AUC [6]

\begin{tabular}{|c|c|}
\hline Nilai AUC & Diklasifikasikan sebagai \\
\hline $0.90-1.00$ & Excellent \\
\hline $0.80-0.90$ & Good \\
\hline $0.70-0.80$ & Fair \\
\hline $0.60-0.70$ & Poor \\
\hline $0.50-0.60$ & Q Fail \\
\hline
\end{tabular}

IJEIS Vol. 6, No. 1, April 2016 : 37 - 46 


\section{HASIL DAN PEMBAHASAN}

Pengujian pada segmentasi tulang kortikal dilakukan menggunakan data masukkan berupa citra dental panoramic radiograph sebanyak 21 citra. Citra ini akan dibandingkan baik tulang kortikal kanan dan tulang kortikal kirinya dengan hasil segmentasi secara manual untuk kemudian dihitung ketepatan dan ketidak tepatannya.

Tabel 2 Akurasi, sensitifitas dan spesifitas pada tulang kortikal kanan

\begin{tabular}{|c|c|c|c|c|c|c|c|c|}
\hline No & Citra & TP & FP & TN & FN & $\begin{array}{c}\text { Akurasi } \\
(\%)\end{array}$ & $\begin{array}{c}\text { Sensitifitas } \\
(\%)\end{array}$ & $\begin{array}{c}\text { Spesifitas } \\
(\%)\end{array}$ \\
\hline 1 & 19 & 1131 & 127 & 2694 & 144 & 93,38 & 88,71 & 95,50 \\
\hline 2 & 20 & 651 & 145 & 3174 & 126 & 93,38 & 83,78 & 95,63 \\
\hline 3 & 21 & 1086 & 105 & 2855 & 50 & 96,22 & 95,60 & 96,45 \\
\hline 4 & $22 \mathrm{a}$ & 1004 & 110 & 2784 & 198 & 92,48 & 83,53 & 96,20 \\
\hline 5 & $22 \mathrm{~b}$ & 732 & 95 & 3064 & 205 & 92,68 & 78,12 & 96,00 \\
\hline 6 & $24 \mathrm{a}$ & 1071 & 189 & 2768 & 68 & 93,73 & 94,03 & 93,61 \\
\hline 7 & $25 \mathrm{a}$ & 933 & 339 & 2315 & 509 & 96,53 & 94,21 & 81,11 \\
\hline 8 & $25 \mathrm{c}$ & 599 & 107 & 2896 & 494 & 85,33 & 85,40 & 96,44 \\
\hline 9 & 27 & 1309 & 199 & 2507 & 81 & 93,16 & 94,17 & 92,65 \\
\hline 10 & $29 \mathrm{~b}$ & 1377 & 215 & 2425 & 79 & 92,82 & 94,57 & 91,86 \\
\hline 11 & 30 & 1249 & 127 & 2372 & 348 & 88,40 & 87,21 & 94,92 \\
\hline 12 & 31 & 1231 & 213 & 2631 & 21 & 94,29 & 98,32 & 92,51 \\
\hline 13 & $33 \mathrm{a}$ & 1380 & 82 & 2404 & 230 & 92,38 & 85,71 & 96,70 \\
\hline 14 & $33 \mathrm{~b}$ & 1428 & 448 & 2134 & 86 & 86,96 & 94,31 & 82,65 \\
\hline 15 & 48 & 622 & 333 & 2418 & 723 & 74,22 & 84,62 & 87,90 \\
\hline 16 & 50 & 1231 & 205 & 2563 & 97 & 92,63 & 92,69 & 92,59 \\
\hline 17 & 57 & 999 & 193 & 2825 & 79 & 93,36 & 92,67 & 93,61 \\
\hline 18 & 66 & 456 & 461 & 3131 & 48 & 87,57 & 90,48 & 87,17 \\
\hline 19 & $69 \mathrm{a}$ & 1317 & 233 & 2542 & 4 & 94,21 & 99,70 & 91,60 \\
\hline 20 & $69 \mathrm{~b}$ & 1501 & 436 & 1858 & 301 & 82,01 & 83,30 & 80,99 \\
\hline 21 & 76 & 1231 & 373 & 2383 & 109 & 88,23 & 91,87 & 86,47 \\
\hline
\end{tabular}

Tabel 2 merupakan informasi hasil perhitungan ROC perbandingan antara citra hasil segmentasi manual dengan citra hasil segmentasi dengan metode active contour. Prosentase yang dihasilkan dari segmentasi kortikal kanan memiliki akurasi, sensitifitas dan spesifitas sekitar 90\%. Dengan prosentase tertinggi untuk akurasi 96,53\%, sensitifitas 99,70\% dan spesifitas $96,70 \%$. Gambar 6.

Grafik ROC hasil segmentasi active contour ini di tampilkan oleh Gambar 5 dan 


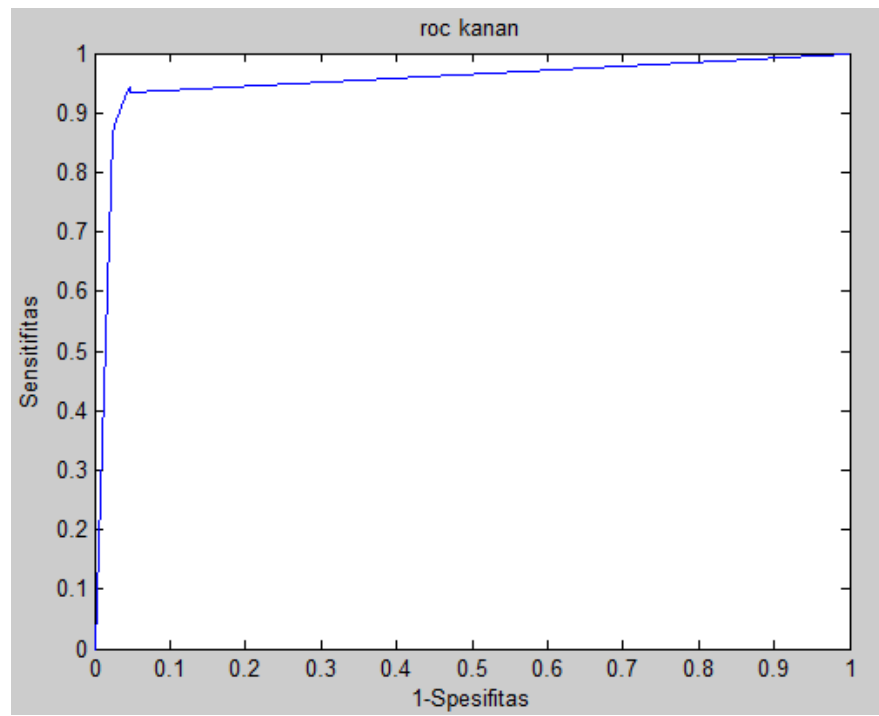

Gambar 5 Grafik ROC kortikal kanan

Gambar 5 merupakan grafik ROC kortikal kanan dengan perbandingan sumbu $\mathrm{x}$ yaitu FPR (False Positive Rate) dan sumbu y yaitu TPR (True Positive Rave). Grafik tersebut menunjukkan bahwa hasil segmentasi kortikal kanan sangat baik karean nilai AUC lebih dari $90 \%$.

Tabel 3 Akurasi, sensitifitas dan spesifitas pada tulang kortikal kiri

\begin{tabular}{|c|c|l|l|l|l|l|l|c|}
\hline No & Citra & TP & FP & TN & FN & akurasi & sensitifitas & spesifitas \\
\hline 1 & 19 & 1033 & 170 & 2857 & 36 & 94,97 & 96,63 & 94,38 \\
\hline 2 & 20 & 602 & 158 & 3043 & 293 & 88,99 & 76,26 & 95,06 \\
\hline 3 & 21 & 934 & 209 & 2893 & 60 & 93,43 & 93,96 & 93,26 \\
\hline 4 & $22 \mathrm{a}$ & 1169 & 61 & 2749 & 117 & 95,65 & 90,90 & 97,83 \\
\hline 5 & $22 \mathrm{~b}$ & 1035 & 338 & 2633 & 90 & 89,55 & 92,00 & 88,62 \\
\hline 6 & $24 \mathrm{a}$ & 1068 & 471 & 2491 & 66 & 86,89 & 94,18 & 84,10 \\
\hline 7 & $25 \mathrm{a}$ & 1336 & 383 & 2341 & 36 & 89,77 & 97,38 & 85,94 \\
\hline 8 & $25 \mathrm{c}$ & 828 & 280 & 2657 & 331 & 85,08 & 71,44 & 90,47 \\
\hline 9 & 27 & 1287 & 200 & 2498 & 111 & 92,41 & 92,06 & 92,59 \\
\hline 10 & $29 \mathrm{~b}$ & 1345 & 95 & 2409 & 247 & 91,65 & 84,48 & 96,21 \\
\hline 11 & 30 & 1004 & 387 & 2258 & 447 & 79,64 & 91,96 & 85,37 \\
\hline 12 & 31 & 1076 & 103 & 2656 & 270 & 90,89 & 79,81 & 96,27 \\
\hline 13 & $33 \mathrm{a}$ & 1329 & 447 & 2095 & 225 & 83,59 & 85,52 & 82,42 \\
\hline 14 & $33 \mathrm{~b}$ & 1036 & 197 & 2753 & 110 & 92,50 & 90,40 & 93,32 \\
\hline 15 & 48 & 1129 & 349 & 2151 & 467 & 80,08 & 70,74 & 86,04 \\
\hline 16 & 50 & 1224 & 283 & 2510 & 79 & 91,16 & 93,94 & 89,87 \\
\hline 17 & 57 & 960 & 29 & 2870 & 237 & 93,51 & 80,20 & 98,99 \\
\hline 18 & 66 & 361 & 259 & 3397 & 79 & 91,75 & 82,05 & 92,92 \\
\hline 19 & $69 \mathrm{a}$ & 1231 & 230 & 2394 & 241 & 88,50 & 83,63 & 91,23 \\
\hline 20 & $69 \mathrm{~b}$ & 1240 & 187 & 2320 & 349 & 86,91 & 78,04 & 92,54 \\
\hline 21 & 76 & 1086 & 337 & 2590 & 83 & 89,75 & 92,90 & 88,49 \\
\hline
\end{tabular}


Tabel 3 menampilkan informasi yang diperoleh dari perhitungan ROC dengan membandingkan citra hasil segmentasi manual dengan citra hasil segmentasi active contour. Hasil perbandingan kortikal kiri nilai prosentase teringgi untuk akurasi yaitu 95,65\%, sensitifitas $97,38 \%$ dan spesifitas $98,99 \%$. Hasil perhitungan ini sangat baik hamper mendekati $100 \%$.

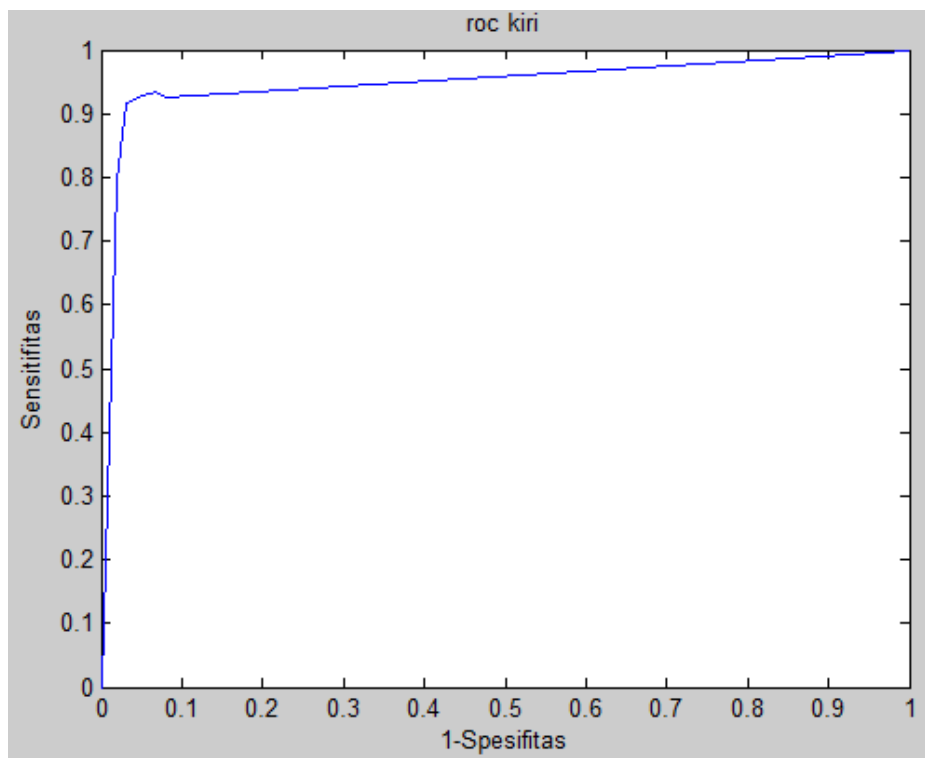

Gambar 6 Grafik ROC kortikal kiri

Informasi yang diperoleh dari Gambar 5 dan Gambar 6, dapat dilihat bahwa nilai AUC hampir lebih dari $90 \%$. berdasarkan Tabel 1, bahwa jika kurva berada lebih dari $90 \%$ berarti sistem tersebut excellent atau sangat baik.

\section{KESIMPULAN}

Kesimpulan yang dapat diambil dari penelitian yang telah diujikan dengan menggunakan metode active contour adalah informasi evolusi kurva yang melingkupi sebuah obyek yaitu tulang kortikal. Hasil kinerja pada proses segmentasi active contour seperti yang tertera pada Tabel 1 untuk kortikal kanan dengan prosentase akurasi 90,67\%, sensitifitas 90,14\% dan spesifitas 91,55\% sedangkan Tabel 2 untuk kortikal kiri dengan prosentase akurasi $89,37 \%$, sensitifitas $86,59 \%$ dan spesifitas $91,23 \%$. Mengacu pada tingkat akurasi hasil segmentasi maka hasil penelitian ini cukup akurat dan dapat digunakan sebagai alternatif metode dalam melakukan segmentasi citra tulang kortikal.

\section{SARAN}

Dalam penelitian ini masih terdapat kekurangan sehingga dalam penelitian selanjutnya disarankan:

1. Penelitian selanjutnya dilakukan dengan menggunakan variabel penelitian dan sampel lebih banyak dan bervariasi untuk memperoleh hasil yang lebih baik dan akurat.

2. Penelitian ini dilakukan sampai diperoleh hasil segmentasi yang diinginkan, sehingga disarankan untuk dilakukan penelitian lanjutan sehingga hasil segmentasi ini dapat digunakan untuk screening dalam bidang medis. 


\section{UCAPAN TERIMA KASIH}

Penulis mengucapkan terima kasih kepada Suami, orang tua dan anak yang telah memberikan dukungan dan doa terhadap penelitian ini.

\section{DAFTAR PUSTAKA}

[1] Arifin, A. Z., Asano, A., Taguchi, A., Nakamoto, T., Ohtsuka, M., Tsuda, M., Kudo, Y. and Tanimoto, K., 2006, Computer-aided System for Measuring the Mandibular Cortical Width on Dental Panoramic Radiographs in Identifying Postmenopausal Women With Low Bone Mineral Density, International Osteoporosis Foundation and National Osteoporosis Foundation, 17, 753-759

[2] Abidin, Z. dan Arifin, A. Z., 2009, Analisis Kerapatan Trabecular Bone Berbasis Graph Berbobot Pada Citra Panorama Gigi Untuk Identifikasi Osteoporosis, Jurnal TI, 7, 5964

[3] Mardhiyah, A. dan Harjoko, A., 2011, Metode Segmentasi Paru-paru dan Jantung Pada Citra X-Ray Thorax, IJEIS, 1, 2, 35-44.

[4] Sprawls, P. (1995), The Physical Principles of Medical Imaging, 2nd edition, Medical Physics Pub. Corp.

[5] Fawcett, T. (2006), "An introduction to ROC analysis", Pattern Recognition Letters, Vol. 27, hal. 861-874.

[6] Mohanty, A.K., Beberta, S., and Lenka, S.K. (2011), "Classifying Benign and Malignant Mass using GLCM and GLRLM based Texture Features from Mammogram”, International Journal of Engineering Research and Applications (IJERA), Vol. 1, hal. 687-693. 